\title{
Correspondence
}

\section{Bcl-2 Expression in Anaplastic Large Cell Lymphoma}

\section{To the Editor-in-Chief:}

Anaplastic large cell lymphoma (ALCL) is a distinct clinicopathological entity that has been individualized in the Revised European American Lymphoma (REAL) classification. ${ }^{1}$ This entity is defined as a T-cell or null-cell lymphoma expressing CD30 (Ki-1 antigen). Three different subtypes of ALCL have recently been identified: primary systemic anaplastic lymphoma kinase-positive (ALK+) ALCL, ALK - ALCL, and primary cutaneous ALCL. ${ }^{2}$ ALK expression is the consequence of chromosomal translocations involving the ALK gene at 2p23 and the protein is detectable by immunohistochemistry. ${ }^{2}$ The most frequent variant of the translocations implicating ALK is the t(2;5) translocation, which juxtaposes the ALK gene at 2 p23 with the nucleophosmin (NPM) gene at $5 q 35$. $^{2}$ Recently, it has been shown that the NPM/ALK chimeric protein activated the phosphatidylinositol 3-kinase/Akt (PI-3K/ Akt) anti-apoptotic pathway. ${ }^{3}$ Therefore, in case of NPM/ ALK expression, one would expect the $\mathrm{Bcl}-2$ protein to be overexpressed in association with other anti-apoptotic factors. In a previous report published in the Journal, ${ }^{4}$ we found in a short series of cases of NPM/ALK + ALCL that the $\mathrm{Bcl}-2$ protein was not expressed. The recent demonstration by Bai et $\mathrm{al}^{3}$ prompted us to extend our previous series of cases and to look for a possible correlation between $\mathrm{Bcl}-2$ and ALK expression.

To do so, we retrieved 75 cases of ALCL that had been diagnosed in the Hematopathology Department at Purpan Hospital during 1998 and 1999 (reviewed by G. D.). Seventy cases were lymph node biopsies (primary systemic ALK + and ALK - ALCL) and five cases corresponded to primary cutaneous ALCL (ALK-). Tissue samples were processed routinely, ie, fixed in DuboscqBrasil and/or formalin and embedded in paraffin. In all cases, a staining was performed with anti-Bcl-2 (clone 124; DAKO, Trappes, France) and anti-ALK (ALK1 kindly provided by Prof. D. Y. Mason, Oxford, UK) monoclonal antibodies on paraffin-embedded sections using microwave heating. ${ }^{5}$ Among the 70 cases of primary systemic $\mathrm{ALCL}, 58$ tumors expressed ALK and 12 tumors were ALK-negative. All but one case of ALK + primary systemic ALCL were negative for Bcl-2 (57/58). In only one case, there was a faint staining in rare lymphoma cells compared to the strong staining observed in the surrounding small reactive lymphocytes. These results are in keeping with those published by Nakamura et al. ${ }^{6}$ In their series, they failed to detect $\mathrm{Bcl}-2$ in 31 cases of p80
(NPM/ALK) + ALCL. ${ }^{6}$ In the present study, 7 of 12 primary systemic ALK - ALCL and all cases (5/5) of primary cutaneous ALCL were Bcl-2-positive. Again, these results are confirmed in the study by Nakamura et $\mathrm{al}^{6}$ and in a more recent publication by Paulli et $\mathrm{al}^{7}$ dealing with $\mathrm{Cu}$ taneous CD30+ lymphoproliferative disorders.

One can suspect that in NPM/ALK + ALCL, the lack of $\mathrm{BCl}-2$ expression is caused by the overexpression of ALK, but this phenotype is difficult to reconcile with the activation of an anti-apoptotic pathway, as recently demonstrated. ${ }^{3}$ Further studies are needed to understand the downstream pathway of PI-3K/Akt signaling. However, our study confirms the preliminary data indicating the lack of $\mathrm{BCl}-2$ expression in ALK+ ALCL. ${ }^{4,6}$ These data strengthen the recent subdivision of ALCL into three distinct subgroups. $\mathrm{Bcl}-2$ and ALK expression are mutually exclusive, and the lack of $\mathrm{Bcl}-2$ expression may have diagnostic value, in some instances, in differentiating anaplastic cell lymphoma from Hodgkin's disease. As ALCL are sensitive to chemotherapy, our findings are also consistent with the concept that $\mathrm{Bcl}-2$ expression is associated with chemoresistance.

Claire Villalva Fethi Bougrine Georges Delsol Pierre Brousset

Centre Hospitalier Universitaire de Purpan

Toulouse, France

\section{References}

1. Harris NL, Jaffe ES, Stein H, Banks PM, Chan JK, Cleary ML, Delso G, De Wolf-Peeters C, Falini B, Gatter KC: A revised European American classification of lymphoid neoplasms: a proposal from the International Lymphoma Study Group. Blood 1994, 84:1361-1392

2. Stein H, Foss HD, Dürkop H, Marafiotti T, Delsol G, Pulford K, Pileri S Falini B: CD30+ anaplastic large cell lymphoma: a review of its histopathologic, genetic, and clinical features. Blood 2000, 96:36813695

3. Bai Y, Ouyang T, Miething C, Morris SW, Peschel C, Duyster J: Nucleophosmin-anaplastic lymphoma kinase associated with anaplastic largecell lymphoma activates the phosphatidylinositol 3-kinase/Akt antiapoptotic signaling pathway. Blood 2000, 96:4319-4327

4. Schlaifer D, Krajewski S, Galoin S, Rigal-Huguet F, Laurent G, Massip P, Pris J, Delsol G, Reed JC, Brousset P: Immunodetection of apoptosis-regulating proteins in lymphomas from patients with and without human immunodeficiency virus infection. Am J Pathol 1996, 149:177185

5. Benharroch D, Meguerian-Bedoyan Z, Lamant L, Amin C, Brugieres L, Terrier-Lacombe MJ, Haralambieva E, Pulford K, Pileri S, Morris SW, Mason DY, Delsol G: ALK-positive lymphoma: a single disease with a broad spectrum of morphology. Blood 1998, 91:2076-2084

6. Nakamura S, Shiota M, Nakagawa A, Yatabe Y, Kojima M, Motoori T, 
Suzuki R, Kagami Y, Ogura M, Morishima Y, Mizoguchi Y, Okamoto M, Seto M, Koshikawa T, Mori S, Suchi T: Anaplastic large cell lymphoma: a distinct molecular pathology entity. A reappraisal with special reference to p80 NPM/ALK expression. Am J Surg Pathol 1997, 21:1420-1432

7. Paulli M, Berti E, Boveri E, Kindl S, Bonoldi E, Gambini C, Rosso R, Borroni G, Straccapansa V, Magrini U, DeCoteau J, Krammer PH Moller P, Kadin ME: Cutaneous CD30+ lymphoproliferative disorders: expression of bcl-2 and proteins of the tumor necrosis factor receptor superfamily. Hum Pathol 1998, 29:1223-1230

\section{Formation of Granulomas in the Lungs of Severe Combined Immunodeficient Mice after Infection with Bacillus Calmette-Guerin}

\section{To the Editor-in-Chief:}

It has been reported that $T$ cells are involved in the process of granuloma formation and may be necessary to induce the formation of granulomas. ${ }^{1}$ However, in an issue of The American Journal of Pathology, North and Izzo showed the formation of granulomas in severe combined immunodeficient (SCID) mice, which are not able to generate efficient $T$ and $B$ cells, after infection with Bacillus Calmette-Guerin (BCG). ${ }^{2}$ These granulomas were found in spleen and liver. Moreover, the authors described a deficiency of these SCID mice to form granulomas in the lungs after inoculation with $\mathrm{BCG}^{2}$ In an attempt to establish a granuloma model to analyze the process of granuloma formation, we intravenously inoculated SCID mice with BCG (strain Connaught) for means of control and examined the animals histomorphologically after 30 days.

Three 10- to 12-week-old female C.B. $-17^{\text {scid/scid }}$ mice were housed in filter-top cages in an incubator with a constant horizontal flow of filtered air and supplied with food and water ad libitum. The mice were inoculated intravenously with BCG $\left(10^{8} \mathrm{CFU}\right.$ per animal; courtesy of E. Richter, National Reference Center for Mycobacteria, Borstel, Germany). The mice were sacrificed 28 to 30 days after inoculation, and the organs were kept in buffered formaldehyde solution ( $4 \% \mathrm{vol} / \mathrm{vol})$. The tissue was paraffin-embedded, sliced, and hematoxylin-and-eosinstained. Visualization of BCG in the tissues was performed by Ziehl-Neelsen staining.

With regard to the formation of granulomas in spleen and liver, we reproduced the results obtained in the study of North and Izzo. ${ }^{2}$ Furthermore, in accordance with previous results, we found isolated alveolar macrophages infected with BCG in the lungs of these mice. ${ }^{2}$ However, we also observed the generation of well formed granulomas in the lungs of these mice. These granulomas were not just aggregations of alveolar macrophages, but were morphologically comparable to the granulomas found in spleen and liver (Figure 1a). Inside the pulmonary granulomas, acid fast bacilli were detected by Ziehl-Neelsen staining (Figure 1b) and identified as mycobacteria from the Mycobacterium tuberculosis complex by means of polymerase chain reaction targeting mycobacterial $16 \mathrm{~S}$ rDNA. ${ }^{3}$ This demonstrates that, upon infection with BCG, SCID mice can produce pulmonary granulomas.

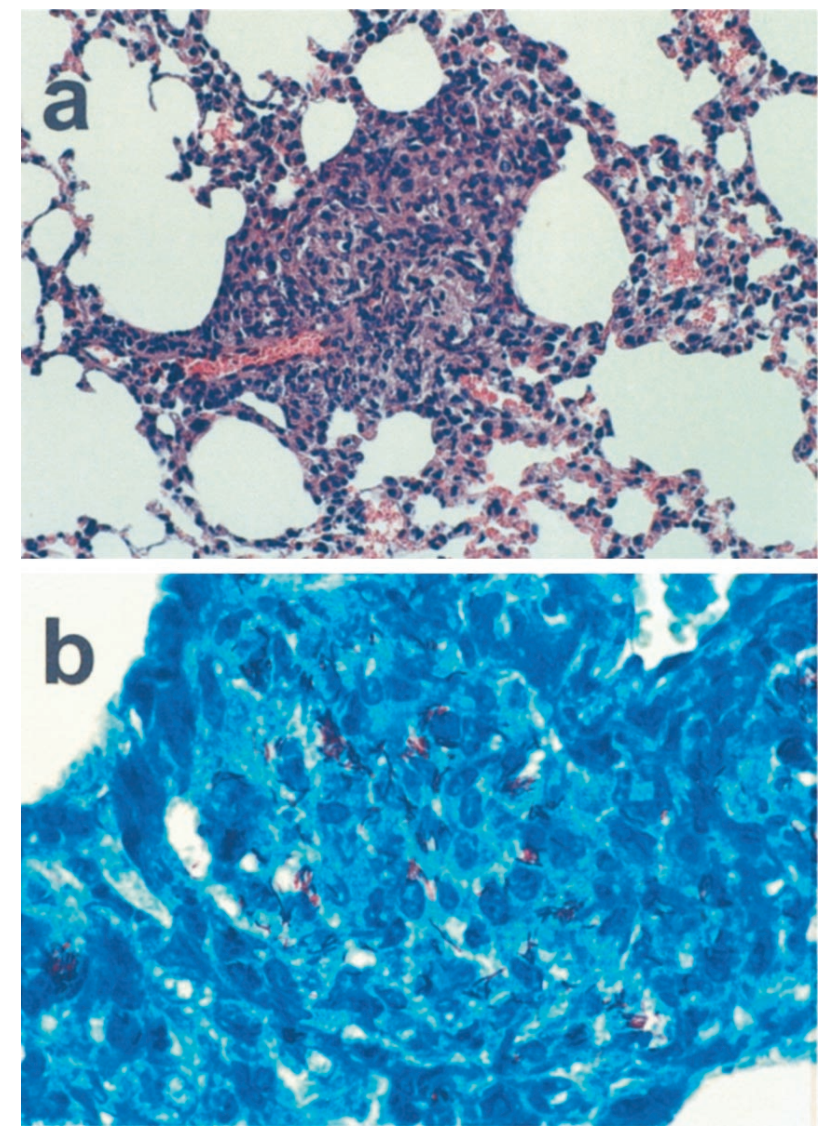

Figure 1. Sections of BCG-induced granulomas in the lungs of a SCID mouse. a: Low-power micrograph $(\times 125)$ of a hematoxylin-and-eosinstained section showing a granuloma. b: High-power micrograph $(\times 500)$ of a Ziehl-Neelsen-stained section showing the infection with BCG inside the granuloma.

Besides tumor necrosis factor- $\alpha$ release, the delivery of interferon- $\gamma(\mathrm{IFN}-\gamma)$ is an important prerequisite for granuloma formation and the eradication of the bacteria. $^{4,5}$ In immunocompetent mice the most important source of IFN- $\gamma$ is Th1 cells. In a recent publication, it was demonstrated that the development of T-cell-independent granuloma is reliant on the induction of IFN- $\gamma$ release by natural killer (NK) cells. ${ }^{6}$ The induction of NK-cell IFN- $\gamma$ release is dependent on the release of interleukin-12 and -10 by macrophages. ${ }^{7,8}$ In a model of Pneumocystis carinii infection, it was demonstrated that although alveolar macrophages are able to stimulate NK cells to release IFN- $\gamma$, they are inferior compared to splenic macrophages. ${ }^{8}$

North and Izzo used the BCG strain Pasteur, so it can be speculated that there might be strain-specific differences in the induction of IFN- $\gamma$-inducing factors by macrophages in the lung, liver, and spleen, since the number of bacteria injected and the time spans of infection have been comparable.

Our experiments demonstrate that the presence of $T$ cells is not mandatory for the generation of pulmonary granulomas in SCID mice. We conclude that SCID mice infected with BCG are capable of generating granulomas in the lungs. 